\title{
A Clinical Recommendation System to Maternity Care
}

\begin{abstract}
Nowadays in healthcare, the Clinical Decision Support Systems are used in order to help health professionals to take an evidence-based decision. An example is the Clinical Recommendation Systems. In this sense, it was developed and implemented in Centro Hospitalar do Porto a pre-triage system in order to group the patients on two levels (urgent or outpatient). However, although this system is calibrated and specific to the urgency of obstetrics and gynaecology, it does not meet all clinical requirements by the general department of the Portuguese HealthCare (Direção Geral de Saúde). The main requirement is the need of having priority triage system characterized by five levels. Thus some studies have been conducted with the aim of presenting a methodology able to evolve the pre-triage system on a Clinical Recommendation System with five levels. After some tests (using data mining and simulation techniques), it has been validated the possibility of transformation the pre-triage system in a Clinical Recommendation System in the obstetric context. This paper presents an overview of the Clinical Recommendation System for obstetric triage, the model developed and the main results achieved.
\end{abstract}

\section{INTRODUCTION}

Currently, in health institutions, there is an increasing amount of information and due the needs to make decisions as correct as possible, emerges the Decision Support Systems (DSS) as a way of supporting the decisions of healthcare professionals based on evidences. In this context are inserted the Clinical Recommendation Systems, whose objective is the use of various computational techniques to achieve a particular purpose (Mackway-Jones K., 1997) (Filipe Portela César Quintas, José Machado, José Neves, $\&$ Santos, 2013) and recommend a clinical action.

Furthermore, the triage systems used in hospital emergency units may be considered a Clinical Recommendation System. In the case of Centro Hospitalar do Porto (CHP), the triage system aims to select the type of patients in terms of clinical urgency, prioritizing the speed of response to treatment, the type of assistance and response resources to the level of urgency. So patients with a higher level of urgency and with increased risk of worsening of the disease, are attended as soon as possible. The most commonly used triage systems are those with five levels of severity, such as the Emergency Severity Index (ESI), the Manchester Triage System (MTS) and the Canadian Triage Acuity Scale (CTAS). The main limitation of this type of scales is the lack of flexibility, since usually they are used only in general emergency units and they are not specific for other units (Murray, Bullard, \& Grafstein, 2004) (Portela et al., 2013). Due to this lack of flexibility for specific specialties, particularly for the obstetrics specialty, a pre-triage system was developed in 2010 in order to categorize the patients on two levels: Urgent (URG) and Consultation (ARGO) (Portela et al., 2013). It should be mentioned that this system only performs a routing triage. This system can forward the patient to the urgency (URG) - if the clinical features justify it, or for consultation - in the less urgent cases.

On the other hand, it is currently recommended by the general department of the Portuguese HealthCare (Direção Geral de Saúde (DGS)), more specifically by the Comissão Nacional da Saúde Materna, da Criança e do Adolescente (CNSMCA), the use of the priority triage system with five priority levels in the obstetric emergency units (Infantil, 2013).

Having in consideration these two factors, it was developed one set of studies involving Data Mining and Simulation techniques in order to evaluate if it would be possible transforming the existing pre-triage 
system in a Clinical Recommendation Triage System for Obstetric (CRTSO). (Pereira, Brandão, Salazar, et al., 2014) (Abelha, Pereira, Brandão, Portela, Santos, \& Machado, 2014)

In this article is exposed the proposed CRTSO, as well as all the methodology used in its construction.

Apart from the introduction this article consists of five section. The second section presents the Background and Related Work. In the third section it is presented the research methodology used and the methods used for the development of CRTSO. In the fourth section is presented the CRTSO developed as well as some adjustments that are necessary to perform the same be functional. In the fifth section are discussed some crucial points and presented the main conclusions. Finally, the sixth section are presented the future research directions.

\section{BACKGROUND AND RELATED WORK}

In this section it is presented a little background of the project then it is presented the theoretical aspects of the main triage systems existing in the world.

\section{Case study contextualization and the Pre-triage System}

This project of designing a CRTSO it was developed in partnership with the Centro Hospitalar do Porto (CHP), more specifically with the Centro Materno Infantil do Norte (CMIN), old Maternidade Júlio Dinis (MJD). CMIN was inaugurated in this year (2014) and covers the needs associated with the care of paediatrics, neonatology, gynaecology and obstetrics (GO). The CMIN is responsible for the inpatient unit, intensive and intermediate care, diagnostic areas, day hospital, births block and has a GO emergency department (Portela et al., 2013).

Due to the inefficiency of the Manchester Triage System (MTS) to triage specific cases, most concretely GO, in 2010 it was implemented a specific pre-triage system for obstetrics emergency department. This system is characterized by a set of discriminators for the obstetrics urgency allowing a patients triage in two levels: Urgent Consultation (ARGO) and Urgent (URG) (Abelha, Pereira, Brandão, Portela, Santos, Silva, et al., 2014). In addition, this system is also characterized by specific six flowcharts (Pregnant ("Yes"), Postpartum Women ("No", "Yes"); Not Women ("No," No"); Pregnant Maybe ("Maybe); Voluntary Interruption of Pregnancy (VIP) ("To IGO"); Cardiotocography (CTG) ("To CTG")). This measure allowed a significant reduction (7\%) of women at the obstetric emergency department as can be seen in Improving Quality of Services in Maternity Care Triage System (Abelha, Pereira, Brandão, Portela, Santos, Silva, et al., 2014). This pre-triage system is supported by the Agency for Integration, Diffusion and Archive Clinic and Medical Information (AIDA), the interoperability platform of CHP (Peixoto, Santos, Abelha, \& Machado, 2012). This interoperability platform is based on the use of intelligent agents to enable communication among different systems. This multi-agent system allows the standardization of clinical systems and overcomes medical and administrative complexity inherent to different sources of information. (Pereira, Brandão, Portela, et al., 2014).

\section{Triage Systems}

As mentioned there are several triage systems currently implemented in healthcare institutions. However, the main limitation of this type of triage systems is the lack of flexibility, i.e., they are not able to respond 
to the requirements of specific emergency departments (Smithson et al., 2013). One such instance, are the patients that fall in the gynaecology and obstetrics specialties. They are characterized by specific symptoms and signs that are not evaluated by the general triage systems available today.

A literature review was carried out about the triage systems most used in the GO Units. In this case highlights the Manchester Triage System (MTS) and Obstetric Triage Accuracy Scale (OTAS). Manchester Triage System (MTS) is a general priorities triage system implemented in the majority of Portuguese and European institutions and Obstetric Triage Accuracy Scale (OTAS) is an obstetric priorities triage system.

\section{Manchester Triage System}

The Manchester Triage System was introduced in the United Kingdom (UK) in 1996 and quickly became widespread in Europe. In mid of 2000 it was implemented in the United States of America (Portela et al., 2013). This system, as most triage systems, aims to identify in a practical and systematic way the severity criteria indicating the clinical priority of a patient should be treated as well as the respective maximum waiting time these patients should be subject. They include a set of fifty two flowcharts, containing a specific set of discriminators that associates the patients to a given urgency class, as can be seen in table 1 .

Table 1- MTS Nomenclature (adapted from (Grupo Português de Triagem, 2002)).

According to the CNSMCA evaluating the advantages and disadvantages of MTS in relation to obstetrics proved to be a difficult task. However, it can be identified that the flowchart 34 ("Pregnancy") is inappropriate for obstetric triage. Furthermore, it was identified some advantages like the fact that the MTS be valid and universally accepted, the patients are triage in to five levels of clinical priorities, and the focus is in the speed and in the objectivity. MTS also enables the monitoring of the implementation and development of quality and efficiency indicators (triage time, waiting time, managed care, list of priorities with the high and hospitalizations, etc.). It should be noted the fact of this system being adopted in Portugal and it is currently linked to the Medical Support System (SAM) (Infantil, 2013).

\section{Obstetrical Triage Acuity Scale}

The Obstetrical Triage Acuity Scale (OTAS) has been shaped by the Canadian Triage and Acuity Scale (CTAS). It was introduced in 1999 and has undergone revisions in years 2006 and 2008 (Murray et al., 2004). The CTAS has a high degree of reliability and validity, however, this only includes a limited number of parameters obstetric which, in turn, does not reflect the diversity of women that go to obstetric triage units. Thus, in order to allow the creation of a tool encompassing a wide variety of patients in the obstetric units it was developed the OTAS. The parameters evaluated are shown in Table 2.

Table 2: OTAS Nomenclature (adapted from (Smithson et al., 2013)).

Thus, OTAS revised five specific parameters of pregnant women: Working Labour and Fluid, Haemorrhage, Hypertension, Fetal Assessment, other (Smithson et al., 2013). In this follow-up it was formed an expert group of physicians and nurses and it was analysed the classification system in order to safeguard the accuracy and integrity of the obstetric discriminators defined. 
OTAS is the first comprehensive obstetric tool with an accurate classification, establishing reliability and validity in terms of obstetric triage. It is a renowned scale and already has a wide application in various obstetric triage units and general emergencies. OTAS provides care to a significant number of women in the obstetrics specialty (Smithson et al., 2013).

In general, this system has the advantage of considering separately the maternal and fetal reviews and separates the pregnancy labour from the pathology. This system is also well-structured for obstetrics in the definition of signs, symptoms and timing of care.

However, this system is not implemented in Portugal and it is not allowed a practice assessment, so it is unknown the OTAS compatibility with the existing systems in the Portugal GO Emergency Department (Infantil, 2013).

\section{MATERIALS, METHODS AND METHODOLOGIES}

Being this project based in scientific studies, it was followed a research methodology and used a set of materials and methods in order to achieve the best model.

\section{Research Methodology}

The project presented throughout this chapter was developed using the research methodology Design Research (DR). The DR purpose is to guide and validate the construction of artefacts. This presupposes the action of a particular study based in a real problem. In this case, there is a problem which is need to understand, design a solution (artefact) and assess the solution. In this sense, the researcher is not a mere observer but an individual who acts in the research context. He seeking to understand a given reality by using their creative potential to create solutions to real problems or needs (Wang \& Hannafin, 2005). So this methodology is divided into five sequential steps: Awareness of Problem, Suggestion, Development, Evaluation and Conclusion. In this sense and following this methodologies it was developed CRTSO.

\section{Development Methodology of the Clinical Recommendation Triage System for Obstetric}

To develop a CRTSO emergency departments, they were carried out several steps to assess (technically and scientifically) the feasibility of the proposal presented in section entitled by Triage Systems.

The procedures performed are shown below:

Literature Review: Initially a survey was conducted about the existing triage systems in the Portuguese and World hospitals. In this context it was concluded that MTS are the most used in the Portuguese reality, and therefore, more suitable for analysis (Infantil, 2013). Specifically, the OTAS System constitutes a world reference for obstetric triage (Smithson et al., 2013). 
Development of a CRTSO proposal: In practical terms it was evaluated the evolution possibility of the pre-triage system into a CRTSO. First in the article entitled as Improving Quality of Services in Maternity Care Triage System (Abelha, Pereira, Brandão, Portela, Santos, Silva, et al., 2014) was presented the pre-triage system, their specific flowcharts and discriminators. Subsequently the process of evolution to a CRTSO it was evaluated by Data Mining (DM) techniques. In the article entitled as PreTriage Decision Support Improvement in Maternity Care by means of Data Mining (Pereira, Brandão, Salazar, et al., 2014) it was proven that the pre-triage system is calibrated for the patients triage on two levels (URG and ARGO), however it was found that the pre-triage system needs for some improvements. That said, it was developed a simulation algorithm that intended to simulate a triage system with five priority levels. This algorithm was developed having as base the pre-triage system. In general as shown in the article entitled Simulating A Multi-Level Priority Tri-age System For Maternity Emergency (Abelha, Pereira, Brandão, Portela, Santos, \& Machado, 2014) it was concluded that it is viable the transformation of the pre-triage system in to a CRTSO. After the application of the algorithm developed to the data provided by the existing pre-triage system it was found that there are patients who fall into all levels of the priorities designed. This conclusion can also be withdrawn by observing the graph presented in the Figure 1.

Figure 1 - Results of pre-triage system and the simulated system grouped by number of patients, for maximum waiting time and time average waiting (adapted from (Abelha, Pereira, Brandão, Portela, Santos, \& Machado, 2014)).

As can be seen in Graph of Figure 1 relating the results obtained by pre-triage System and polo simulated system it appears that much of the URG pregnant become level 3 and ARGO become level 5, give the finalization of the processing the viability of pre-triage system in a CRTSO.

After these preliminaries studies, the proposal was developed using:

- OTAS system, because it already is a specific system of obstetric triage (Smithson et al., 2013).

- MTS system, because it is a standard Triage System for general emergency departments.

- Empirical knowledge of health specialists in obstetric area that currently work, or have already exercised triage activities.

Model evaluation: In the evaluation process and after being designed the proposal of clinical CRTSO, they were performed 3 joint meetings with all the professionals involved, with the following order of work:

- At the first meeting it was made known to all members the system proposal.

- At the second meeting and after everybody involved in the work be framed on the subject, there was made an analysis of all flowcharts in order to proceed to their medical and scientific evaluation;

- At the third meeting it was reached an agreement on the proposal made.

This process was time consuming but rewarding, since the interaction made between the information system professionals and the healthcare professionals it was possible to obtain a final model sensitive and adapted to a specific reality: gynaecology service. 


\section{CLINICAL RECOMMENDATION TRIAGE SYSTEM FOR OBSTETRIC}

This section presents the transformation model of pre-triage system into a CRTSO. Initially it is shown the nomenclature chosen for the CRTSO. Then it is presented the CRTSO developed. In the last topic are presented overall adjustments to the proposal be functional.

\section{Nomenclature}

The analysis of the nomenclature and definitions currently in use by the existing triage systems revealed the existence of some similarities but also some differences between the pre-triage systems. Two of the systems in analysis were the MTS and OTAS. The terms used were presented in Tables 1 and 2 respectively. With the analysis of these two systems was possible to quickly reach an agreement on a new nomenclature. In this regard, to each one of the new triage categories was assigned a level, a name, a colour, a target time (maximum wait time for the admission) and a re-evaluation time, as presented in Table 3.

Table 3 - Clinical Recommendation Triage System For Obstetrics Nomenclature

This initial nomenclature will be re-calibrated in the future after testing the model by using real data. The main changes can be essentially in the target time and in the reassessment time.

\section{Model}

Three different models have been developed taking into account the types of users: Pregnant ("Yes"), Postpartum, ("No", "Yes"), Not Postpartum Women ("No", "No") and Maybe Pregnant ("Maybe" ), as described in the article entitled Improving Quality of Services in Maternity Care Triage System (Abelha, Pereira, Brandão, Portela, Santos, Silva, et al., 2014).

Due to similarities between issues/discriminators the six flowcharts were grouped in three different flowcharts, and the flowcharts "To VIP" and "To CTG" were extinguished of the triage system as is explained below.

As part of this work and due to confidentiality duties, only it is presented the model for the flowchart Pregnant ("Yes"). Although this the other two models also have been developed.

In Table 4, is represented the model developed for the flowchart of patients identified as Pregnant ("Yes").

Table 4-Model of the Clinical Recommendation Triage System for Obstetrics, Flowchart Pregnant patients ("Yes").

In this system are evaluated some parameters relevant to distinguish the priority of pregnant woman ("Yes") taking into account the clinical characteristics at the triage time: labour, haemorrhage, hypertension, fetal assessment, the Glasgow Coma Scale (GCS), pain scale, fever and others variables as can be seen in Table 4. 
In order to changing the pre-triage system to a CRTSO with five priority levels, the existing pre-triage system requires some changes:

\section{Change in nomenclature of the existing discriminators:}

- Uterine contractions > Rhythmic and Painful Contractions;

- Nausea / Vomiting > Uncontrollable Vomiting;

- Change the Colour of the skin > Jaundice;

- In general, the categorization of the other parameters evaluated in Table 4 was trivial between the pre-triage system and OTAS.

\section{Add new discriminators:}

- Discharge;

- Itching;

- Other conditions (contact with varicella and rubella);

- To IGO or Not Evolutionary Pregnancy: Women for IGO should be included in the type of pregnant patients. If this is not associated with a medical condition should be inserted in less urgent level (level 5);

- Dyspnoea;

- Imminent birth;

\section{Changing the type of variable:}

- The parameters "Weeks of Pregnancy", "Blood Pressure" and "Fever" should become numeric (permit the choice of a value or enter a numerical value only).

\section{General Adaptations}

After the models development it was identified a set of overall adjustments to be applied to the three proposed models (one for each flowchart).

The first adjustment is in the fact of the flow discriminators described in the previous subsection (model) are not performed sequentially in the pre-triage system. Thus, it is suggested that during the implementation of this model should be imposed a condition preventing the system reduce the priority, or a recast where they are asked first the main discriminator and so forth, as can be seen in Figure 2.

Figure 2 - Proposal for general Clinical Recommendation System for obstetric triage.

In Figure 2 is defined a set of priority questions, that must be doing to the patients when they are admitted to the emergency department. First should be asked to patient the reason for the visit the emergency department. In the case of bean emergent situation the patient is attended immediately, i.e., he is not submitted to the triage process.

Then the clinical professional should try to see what type of patient she is. She can be a Pregnant Woman ("Yes"), Postpartum Women ("Yes", "No") or not Pregnant Women ("No", "No") / Pregnant Maybe ("Maybe"). That said, should be carried out a set of priority questions, according to the chosen flowchart. Finally should be recommended the priority level. 
The second adjustment is to the patients identified as Urgent Consultation (ARGO) in the pretriage system. They should be distinguished with the Blue priority (level 5) and sent for urgent consultations as happen actually with pre-triage system. On the other hand, patients that are assigned to category Urgent (URG) in the pre-triage system must be distributed among the remaining four levels of priorities proposed (Red (level 1), Orange (level 2), Yellow (level 3) and Green (level 4)) being then referred to the obstetric emergency room according to their clinical condition (priority).

With this condition it can be can recommended a referral of the patients in more detail and more effectively, especially for urgent patients. They are now divided by different levels of clinical care.

Finally the classes of patients "To CTG" and "To IGO" were removed from the CMIN obstetric emergency. The patients "To CTG" are not considered urgent once the exams and pregnancy monitoring process are not an urgent situation. Relatively to the patients "To IGO", they are not also considered urgent cases, unless exceptions where the patients present situations inspiring urgent care (e.g. vaginal bleeding). In these situations the women should be placed on pregnant woman ("Yes") flowchart.

\section{DISCUSSION AND CONCLUSION}

The possible implementation of a CRTSO will provide significant benefits for CMIN while health institution as well as to the patients who use this health institution. It allows a patient categorization in five levels according to the level of clinical needs, prioritizing their care according their condition.

For the development of this proposal it was required an extensive work of literature review, planning, development and evaluation of the proposed CRTSO. Throughout this section it is made an analysis between the work developed and guidelines suggested by the CNSMCA regarding to the obstetric triage.

They were evaluated four points:

1) Scientific gathering information on the various existing systems: for this process it was conducted a scientific review on the existing triage systems in worldwide. In sub section Triage System were described the theoretical aspects of MTS and OTAS Systems and in the article entitled by Improving Quality of Services in Maternity Care Triage System (Abelha, Pereira, Brandão, Portela, Santos, Silva, et al., 2014) is described the pre-triage system implemented in CMIN.

2) Knowledge criteria of the Portuguese reality through contact with triage systems in use: on this topic, according to the study done by CNSMCA where a survey was conducted at 38 institutions Portuguese about the obstetric triage, it was identified that 34 of these institutions has the obstetric urgency and the general urgency separated. Of these, only 12 performed the obstetric triage. Usually it turns out the existence of these systems in hospitals where the flow of patients in obstetric emergency is high. It was also detected that there is a wide variety software with adaptations made as is the ALERT software with MTS, or very simplistic triage systems that only differentiate between 
urgent and non-urgent patients (Portela et al., 2013) (Infantil, 2013) (Abelha, Pereira, Brandão, Portela, Santos, Silva, et al., 2014).

\section{3) Defining criteria for the CRTSO developed:}

a) The most scientific and consensually internationally valid: in this context the two systems valid at international level are: the OTAS and MTS. The first was developed for triage in obstetric emergency. The second is recognized at international level and are in the Portuguese healthcare institutions. Then there is also the pre-triage system, which although not be a global system, their efficiency has been demonstrated in the articles Improving Quality of Services in Maternity Care Triage System (Abelha, Pereira, Brandão, Portela, Santos, Silva, et al., 2014), Pre-Triage Decision Support Improvement in Maternity Care by means of Data Mining (Pereira, Brandão, Salazar, et al., 2014) and Simulating Multi-Level Priority Triage System For Emergency Maternity (Abelha, Pereira, Brandão, Portela, Santos, \& Machado, 2014). It is characterized by a set of discriminators adapted to the CMIN and the reality of an obstetric emergency.

b) Must be compatible with the software applications of the Ministry of Health, i.e. interconnection to existing software level hospitals: Given that the starting point is pre-triage system supported by AIDA which interlinks with other systems SNS (Medical Support System (SAM) Nursing Practice Support System (SAPE), etc.). In the future the CRTSO proposed will take up these features too.

c) Easy to learn and intuitive as possible: The pre-triage system was already implemented in the MJD, since 2010 and was subsequently transferred to the CMIN. Being the CRTSO an adaptation of the pre-triage system, the healthcare professionals at CMIN are much familiarized with the system.

d) Adapted or the ability to adapt to obstetric specialty, i.e., flowchart and discriminated specific for obstetrics: The pre-triage system is characterized by having specific discriminators to obstetrics therefore the developed model also has this valence. In addition to the specific discriminators already used in pretriage system this CRTSO has new discriminators. The existing discriminators, such as those added to the model went through a process of natural discussion to assess their viability.

4) Defining the criteria for who does obstetric: Usually this pre-triage process should be performed by health professionals: Nurse Specialist in maternal and child health or Physician specialist in obstetric. Once the triage process currently is carried out by experts in Obstetric, this feature also will be present in the new CRTSO.

It is important to note that although this CRTSO have been designed based on the MTS, OTAS and pre-triage system of CMIN, should not be classified as a priority triage system but as a Clinical Recommendation System (CRS). CRTSO only allows a recommend forwarding and a 
service order taking into account a range of clinical aspects of patients, however the final decision is always taken by the health professional responsible for this process.

It is therefore concluded that the proposed transformation of the pre-triage system into a CRTSO is a pioneer project with great potentialities. The main goal is not replace the MST but create an alternative to most specific departments as is GO emergency units.

\section{FUTURE RESEARCH DIRECTIONS}

In view of the project success, as future work is suggested one set of sequential steps:

1) Presenting of the this CRTSO in the CMIN to discuss its possible implementation and testing;

2) Contact the Portuguese Group of Triage (Grupo Português de Triagem, 2014), that are the responsible institution for the implementation of triage systems in Portugal, in order to approve the CRTS developed;

3) If approved by those two institutions should proceed to the implementation of the flowcharts associated to the respective discriminators and conditions specified for the transformation considered in the article. If the project is not approved, should be made the necessary changes in order to approve the project, after the changes should be executed again the point 1 of this sequence.

4) Preparation of documents and specific protocols supporting the use of the system implemented, for example, a manual to support the healthcare professional in the triage process.

5) Perform periodic evaluations in order to make timeout adjustments to optimize the speed of attending patients in critical condition. One of the methodology to be followed it was focused in article entitled by Pre-Triage Decision Support Improvement in Maternity Care by means of Data Mining (Pereira, Brandão, Salazar, et al., 2014). This article used DM techniques to obtain prediction models. At same time it was developed a Business Intelligence platform to manage pre-triage indicators. This platform also can incorporate indicators from the CRTSO developed. This Business Intelligence platform can be consulted in the articles entitled by Business Intelligence to Maternity Care (Pereira, Brandão, Portela, et al., 2014) and it allows obtaining Key Indicator Performance (KPI) about the performance of the pre-triage system.

The proposal CRTSO presented in this article aims the implementation in CMIN as a testing phase. However the objective is that in the future may be used by other health institutions that contemplate the obstetric emergency department.

\section{ACKNOWLEDGEMENTS}

This work is funded by National Funds through the FCT - Fundação para a Ciência e a Tecnologia (Portuguese Foundation for Science and Technology) within projects PEst-OE/EEI/UI0752/2014 and PEst-OE/EEI/UI0319/2014. The work of Filipe Portela was supported by a postdoctoral grant associated to FCT project INTCare II - PTDC/EEI-SII/1302/2012. 


\section{REFERENCES}

Abelha, A., Pereira, E., Brandão, A., Portela, C. F., Santos, M. F., \& Machado, J. (2014).

Simulating a multi-level priority triage system for Maternity Emergency. In ESM - 28th European Simulation and Modelling Conference. Porto, Portugal: EUROSIS.

Abelha, A., Pereira, E., Brandão, A., Portela, F., Santos, M. F., Silva, Á., ... Braga, J. (2014). Improving Quality of Services in Maternity Care Triage System. International Journal of EHealth and Medical Communications (IJEHMC).

Filipe Portela César Quintas, osé Machado, A. C. J., osé Neves, A. A. J., \& Santos, M. S. M. F. (2013). Knowledge Acquisition Process for Intelligent Decision Support in Critical Health Care. In Information Systems and Technologies for Enhancing Health and Social Care (p. 55). IGI Global.

Grupo Português de Triagem. (2002). Triagem no serviço de Urgência-Manual do Formador (2 ed.). Lisboa: BMJ Publishing Group.

Grupo Português de Triagem. (2014). Grupo Português de Triagem. Retrieved from http://www.grupoportuguestriagem.pt/jm/ (acessed on 20, September 2014)

Comissão Nacional de Saúde Materna da Criança e do Abolescente (2013). Triagem Obstétricamodelo de Triagem. Lisboa: Direção Geral de Saúde.

Mackway-Jones K., M. J. \& W. J. (1997). ). Emergency triage: Manchester triage group: BMJ.

Murray, M., Bullard, M., \& Grafstein, E. (2004). Revisions to the Canadian Emergency Department Triage and Acuity Scale implementation guidelines. Cjem, 6(6), 421-7. Retrieved from http://www.ncbi.nlm.nih.gov/pubmed/17378961 (acessed on 20, September 2014)

Peixoto, H., Santos, M., Abelha, A., \& Machado, J. (2012). Intelligence in Interoperability with AIDA. In L. Chen, A. Felfernig, J. Liu, \& Z. Raś (Eds.), Foundations of Intelligent Systems SE - 31 (Vol. 7661, pp. 264-273). Springer Berlin Heidelberg. doi:10.1007/978-3-64234624-8_31

Pereira, E., Brandão, A., Portela, C. F., Santos, M. F., Machado, J., \& Abelha, A. (2014). Business Intelligence in Maternity Care. In Proceedings of the 18th International Database Engineering \& Applications Symposium (pp. 352-355). New York, NY, USA: ACM.

Pereira, E., Brandão, A., Salazar, M., Portela, C. F., Santos, M. F., Machado, J., ... Jorge, B. (2014). Pre-Triage Decision Support Improvement in Maternity Care by means of Data Mining. In A. Azevedo \& M. F. Santos (Eds.), Integration of Data Mining in Business Intelligence Systems. Hershey, PA, USA: IGI Global Book. 
Portela, F., Cabral, A., Abelha, A., Salazar, M., Quintas, C., Machado, J., ... Santos, M. F. (2013). Knowledge Acquisition Process for Intelligent Decision Support in Critical Health Care. In \& J. V. R. Martinho, R. Rijo, M. Cruz-Cunha (Ed.), R. Martinho, R. Rijo, M. CruzCunha, \& J. Varajão (Vol. Informatio). Hershey, PA: Medical Information Science Reference.

Smithson, D. S., Twohey, R., Rice, T., Watts, N., Fernandes, C. M., \& Gratton, R. J. (2013). Implementing an obstetric triage acuity scale: interrater reliability and patient flow analysis. American Journal of Obstetrics and Gynecology, 209(4), 287-93. doi:10.1016/j.ajog.2013.03.031

Wang, F., \& Hannafin, M. J. (2005). Design-based research and technology-enhanced learning environments. Educational Technology Research and Development, 53(4), 5-23.

\section{ADDITIONAL READING SECTION}

Filipe Portela César Quintas, osé Machado, A. C. J., osé Neves, A. A. J., \& Santos, M. S. M. F. (2013). Knowledge Acquisition Process for Intelligent Decision Support in Critical Health Care. In Information Systems and Technologies for Enhancing Health and Social Care (p. 55). IGI Global.

Murray, M., Bullard, M., \& Grafstein, E. (2004). Revisions to the Canadian Emergency Department Triage and Acuity Scale implementation guidelines. Cjem, 6(6), 421-7. Retrieved from http://www.ncbi.nlm.nih.gov/pubmed/17378961

Peixoto, H., Santos, M., Abelha, A., \& Machado, J. (2012). Intelligence in Interoperability with AIDA. In L. Chen, A. Felfernig, J. Liu, \& Z. Raś (Eds.), Foundations of Intelligent Systems SE - 31 (Vol. 7661, pp. 264-273). Springer Berlin Heidelberg. doi:10.1007/978-3-64234624-8_31

Portela, F., Cabral, A., Abelha, A., Salazar, M., Quintas, C., Machado, J., ... Santos, M. F. (2013). Knowledge Acquisition Process for Intelligent Decision Support in Critical Health Care. In \& J. V. R. Martinho, R. Rijo, M. Cruz-Cunha (Ed.), R. Martinho, R. Rijo, M. CruzCunha, \& J. Varajão (Vol. Informatio). Hershey, PA: Medical Information Science Reference.

Smithson, D. S., Twohey, R., Rice, T., Watts, N., Fernandes, C. M., \& Gratton, R. J. (2013). Implementing an obstetric triage acuity scale: interrater reliability and patient flow analysis. American Journal of Obstetrics and Gynecology, 209(4), 287-93. doi:10.1016/j.ajog.2013.03.031

Wang, F., \& Hannafin, M. J. (2005). Design-based research and technology-enhanced learning environments. Educational Technology Research and Development, 53(4), 5-23. 


\section{KEY TERMS \& DEFINITIONS}

AIDA - Platform developed to ensure interoperability among healthcare information systems.

Business Intelligence- A technology that uses data analysis tools and applications to help business users make more informed decision.

Clinical Recommendation System - combines several computational techniques to select custom items based on user interests and as the context in which they live.

Decision Support System- A computerized information system used to support decision-making process in an organization or business.

Gynaecology and Obstetrics- is the medical specialty dealing with fields of through only one postgraduate training programmer. This combined training prepares the practicing Gynaecology and Obstetrics to be adept at the care of female reproductive organs' health and at the management of obstetric complications, even though surgery

Interoperability - Autonomous ability to interact and communicate.

Maternity Care - Health institution where patients of gynaecology and obstetrics specialties are admitted.

Pre-Triage System - A triage system has as main aim to improve the quality of care in that it provides a service based on clinical characteristics and the target time.

Triage - the sorting of patients (as in an emergency room) according to the urgency of their need for care

\section{TABLES AND FIGURES}

Table 5- MTS Nomenclature (adapted from (Grupo Português de Triagem, 2002)).

\begin{tabular}{|l|l|l|r|}
\hline Number & \multicolumn{1}{|c|}{ Name } & \multicolumn{1}{c|}{ Colour } & Target time \\
\hline 1 & Emergent & Red & 15 \\
\hline 2 & Very Urgent & Orange & 30 \\
\hline 3 & Urgent & Yellow & 60 \\
\hline 4 & Less Urgent & Green & 120 \\
\hline 5 & Non- Urgent & Blue & \\
\hline
\end{tabular}

Table 6 - OTAS Nomenclature (adapted from (Smithson et al., 2013)).

\begin{tabular}{|l|l|l|r|l|}
\hline \multicolumn{1}{|c|}{ Number } & \multicolumn{1}{|c|}{ Name } & \multicolumn{1}{c|}{ Colour } & Target time & \multicolumn{1}{c|}{ Reassessment } \\
\hline OTAS 1 & Recursive & Red & 0 & Immediate \\
\hline OTAS 2 & Emergent & Orange & 15 & All 10 min \\
\hline OTAS 3 & Urgent & Yellow & 30 & All 15 min \\
\hline
\end{tabular}




\begin{tabular}{|l|l|l|r|l|}
\hline OTAS 4 & Less Urgent & Green & 60 & All 15 min \\
\hline OTAS 5 & Non-Urgent & Blue & 120 & All 60 min \\
\hline
\end{tabular}

Table 7 - Clinical Recommendation Triage System For Obstetrics Nomenclature

\begin{tabular}{|l|l|l|r|l|}
\hline Level & \multicolumn{1}{|c|}{ Name } & \multicolumn{1}{|c|}{ Colour } & \multicolumn{1}{c|}{ Target time } & \multicolumn{1}{c|}{ Reassessment } \\
\hline 1 & Emergent & Red & 0 & Immediate \\
\hline 2 & Very Urgent & Orange & 15 & All 10 min \\
\hline 3 & Urgent & Yellow & 30 & All 15 min \\
\hline 4 & Less Urgent & Green & 60 & All 15 min \\
\hline 5 & Non- Urgent & Blue & 120 & All 60 min \\
\hline
\end{tabular}

Table 8-Model of the Clinical Recommendation Triage System for Obstetrics, Flowchart Pregnant patients ("Yes").

\begin{tabular}{|c|c|c|c|c|c|}
\hline $\begin{array}{l}\text { Triage GO } \\
\text { (pregnant) }\end{array}$ & $\begin{array}{l}\text { 1 } \\
\text { (Emergent) }\end{array}$ & $\begin{array}{l}2 \\
\text { (Very urgent) }\end{array}$ & $\begin{array}{l}3 \\
\text { (Urgent) }\end{array}$ & $\begin{array}{l}4 \\
\text { (Less urgent) }\end{array}$ & $\begin{array}{l}5 \\
\text { (Non- urgent) }\end{array}$ \\
\hline Target Time & Immediate care & $<=15 \min$ & $<=30 \mathrm{~min}$ & $<=60 \mathrm{~min}$ & $<=120 \mathrm{~min}$ \\
\hline Re-assessment & $\begin{array}{l}\text { Continuous } \\
\text { Nursing Care }\end{array}$ & Every 15 min & Every 15 min & Every 30 min & Evert $60 \mathrm{~min}$ \\
\hline Labor/Fluid & $\begin{array}{l}\text { Imminent } \\
\text { birth }\end{array}$ & $\begin{array}{l}\text { Loss of } \\
\text { amniotic fluid. } \\
\text { Rhythmic and } \\
\text { painful uterine } \\
\text { contractions } \\
\text { and week of } \\
\text { pregnancy <35? }\end{array}$ & $\begin{array}{l}\text { - Loss of } \\
\text { amniotic fluid } \\
\text { and Rhythmic } \\
\text { and painful } \\
\text { uterine } \\
\text { contractions }\end{array}$ & & \\
\hline Vaginal bleeding & $\begin{array}{l}\text { - Hemorrhage } \\
\text { (Severe)? }\end{array}$ & $\begin{array}{l}\text { Hemorrhage } \\
\text { (Moderate)? }\end{array}$ & $\begin{array}{l}\text { Hemorrhage } \\
\text { (Scarce)? }\end{array}$ & & \\
\hline Blood Pressure & $\begin{array}{l}\text { (Systolic> } 160 \\
\text { and diastolic> } \\
110) \text { and / or } \\
\text { (headache, visual } \\
\text { changes or } \\
\text { epigastric pain / } \\
\text { right upper } \\
\text { quadrant Pain)? }\end{array}$ & & $\begin{array}{l}\text { - Systolic }>140 \\
\text { and diastolic> } \\
\text { 90) and } \\
\text { (headache or } \\
\text { visual changes } \\
\text { or epigastric } \\
\text { pain / right } \\
\text { upper } \\
\text { quadrant)? } \\
\end{array}$ & $\begin{array}{l}\text { Ref. Tension Rise? } \\
\text { - Systolic }>140 \\
\quad \text { and diastolic }>90 ?\end{array}$ & \\
\hline $\begin{array}{l}\text { Fetal } \\
\text { Assessment }\end{array}$ & & & $\begin{array}{l}\text { - Absence of } \\
\text { fetal } \\
\text { movements? }\end{array}$ & $\begin{array}{l}\text { - Decreased of fetal } \\
\text { movements? }\end{array}$ & \\
\hline $\begin{array}{ll}\text { Glasgow Coma } \\
\text { Scale }\end{array}$ & - Glasgow (3)? & $\begin{array}{ll} & \text { Glasgow (4- } \\
5) ?\end{array}$ & $\begin{array}{l}\text { - Glasgow (6- } \\
\text { 8)? }\end{array}$ & - Glasgow (9-12)? & $\begin{array}{l}\text { - Glasgow (13- } \\
15) \text { ? }\end{array}$ \\
\hline $\begin{array}{l}\text { Pain scale (local, } \\
\text { intensity, } \\
\text { duration) }\end{array}$ & $\begin{array}{l}\text { Pain (10) and } \\
\text { (abdominal } \\
\text { pain or low } \\
\text { back pain or } \\
\text { pain in the } \\
\text { lower } \\
\text { abdomen)? }\end{array}$ & $\begin{array}{l}\text { Pain (7-9 and } \\
\text { (abdominal } \\
\text { pain or low } \\
\text { back pain or } \\
\text { pain in the } \\
\text { lower } \\
\text { abdomen)? }\end{array}$ & $\begin{array}{l}\text { Pain (4-6) and } \\
\text { (abdominal } \\
\text { pain or low } \\
\text { back pain or } \\
\text { pain in the } \\
\text { lower } \\
\text { abdomen)? }\end{array}$ & $\begin{array}{l}\text { Pain (1-3) and } \\
\text { (abdominal pain or } \\
\text { low back pain or } \\
\text { pain in the lower } \\
\text { abdomen)? }\end{array}$ & - $\quad$ Pain $(0) ?$ \\
\hline Fever & & - $>=41,0^{\circ} \mathrm{C}$ & - $38,5-40,9^{\circ} \mathrm{C}$ & - $37,5^{\circ} \mathrm{C}-38,4^{\circ} \mathrm{C}$ & - $<37,4^{\circ} \mathrm{C}$ ? \\
\hline Umbilical cord & - Umbilical cord & & & & \\
\hline
\end{tabular}




\begin{tabular}{|c|c|c|c|c|c|}
\hline prolapse & prolapse? & & & & \\
\hline Other & $\begin{array}{l}\text { - Dyspnoea } \\
\text { - Seizures? }\end{array}$ & $\begin{array}{l}\text { - Lipothymy } \\
\text { - Trauma in } \\
\text { pregnant }\end{array}$ & $\begin{array}{l}\text { - Uncontrollable } \\
\text { vomiting? } \\
\text { - Epigastric pain } \\
\text { / right upper } \\
\text { quadrant and } \\
\text { weeks of } \\
\text { gestation> 20? } \\
\text { - Higher pain 1 } \\
\text { week? } \\
\text { - Jaundice and } \\
\text { gestational } \\
\text { weeks> 20? } \\
\text { - General } \\
\text { condition } \\
\text { (Bad)? }\end{array}$ & $\begin{array}{l}\text { - Epigastric pain / right } \\
\text { upper quadrant and } \\
\text { weeks of gestation } \\
<20 \text { ? } \\
\text { - Jaundice and weeks } \\
\text { gestation <20 } \\
\text { - Urinary symptoms? } \\
\text { - General condition } \\
\text { (Average)? }\end{array}$ & $\begin{array}{l}\text { - General } \\
\text { condition } \\
\text { (Good) } \\
\text { - To IGO or not } \\
\text { Evolutionary } \\
\text { Pregnancy } \\
\text { - Combur? } \\
\text { - Other situations } \\
\text { (contact with } \\
\text { chickenpox and } \\
\text { rubella)? }\end{array}$ \\
\hline
\end{tabular}

